\title{
Flipped Classroom with Challenge-Based Learning Model on an Online Streaming Ecosystem to Develop Coping Skills in Cyberbullying
}

\author{
Phisit Pornpongtechavanich, Kawitsara Eumbunnapong, and Pallop Piriyasurawong
}

\begin{abstract}
The purposes of this research were: 1) to synthesize documents and international research on designing flipped classroom with challenge-based learning model on an online streaming ecosystem to develop coping skills in cyberbullying; 2) to design a flipped classroom with challenge-based learning model on an online streaming ecosystem to develop coping skills in cyberbullying; (3) to assess the suitability of the flipped classroom with challenge-based learning model on an online streaming ecosystem to develop coping skills in cyberbullying. Ten experts were selected using a specific selection: they had more than five years of relevant experience in the field with expertise in educational technology and information technology. The assessment ensures the suitability of the flipped classroom model with eco-challenging, for online learning to improve cyber bullying coping skills. The results showed that 41 international papers and research studies were synthesized, which concluded that there were eight factors that contribute to cyberbullying. The factors used for online streaming consisted of eight elements. The cyberbullying skills development process used a flipped classroom model and challenging learning to form a new learning model. When the components were completed, they were designed and evaluated. It was found that the flipped classroom with online learning ecosystem improves cyber bullying skills. It is highly suitable for developing cyberbullying prevention skills.
\end{abstract}

Index Terms-Flipped classroom, online streaming, cyberbullying, challenge-based learning.

\section{INTRODUCTION}

In today's world, most people have access to the internet. In 2021, a survey of the Thai population's digital and internet usage behavior found that $69.5 \%$ of the population uses the internet. This ranks ninth in the world. Regarding mobile internet usage per day, it is ranked third in the world. Most of the Thai population watch streaming content: $60.8 \%$ per month; social media is used by $78.7 \%$ of the population and for 2.48 hours per day. Although there is high internet access, $26.2 \%$ of the Thai population are concerned about their

Manuscript received March 26, 2021; revised June 4, 2021. This work was supported in part by Rajamangala University of Technology Rattanakosin Wang Klai Kangwon Campus (RMUTR_KKW), Thailand.

P. Pornpongtechavanich is with the Department of Information Technology, Faculty of Industry and Technology, Rajamangala University of Technology Rattanakosin Wang Klai Kangwon Campus, Thailand (corresponding author; e-mail: phisit.kha@rmutr.ac.th).

K. Eumbunnapong is with Faculty of Medicine Siriraj Hospital, Mahidol University, Thailand (e-mail: kawitsara.kra@mahidol.edu).

P. Piriyasurawong is with Faculty of Technical Education, King Mongkut's University of Technology North Bangkok (KMUTNB), Bangkok, 10800, Thailand (e-mail: palloppi@gmail.com). personal information [1], which can be seen from the fact that the Thai population uses the internet on social media via social networks. As a result of the large number of internet users on social media, the results of the opinions expressed by social media are easy to do, lack of good data analysis. This can be both positive and negative, resulting in intentional and unintentional cyberbullying.

Survey results from the Digital Intelligence Quotient Institute, Singapore, used data from a sample of 44,000 Thai students in grades 4-6, from 450 schools, in all regions of Thailand during 2018-2019. This was used to create a Child Online Safety Index to study which children are at high risk of being cyberbullied and considering the number of times that it occurred. It found that Thai children 8-19 years. There are six areas of potential online dangers as follows: 1) cyberbullying; 2) using technology without discipline; 3) risk from inappropriate content; 4) stranger exposure; 5) cyberharassment; 6) cybervictimization.

The survey found that $41 \%$ of Thai children have been cyberharassed online, while the number of children in other countries is $39 \%$. While the same proportion of Thai boys and girls have been cyber threatened, boys are $45 \%$ more likely to be victims of cyberattacks than girls at $40 \%$. Further, $40 \%$ of children aged 13 and over have been cyberbullied; this is similar to $39 \%$ in other countries, $43 \%$ of children 13 years and over, and cyberbullying of girls accounted for $43 \%$. While $37 \%$ of boys experience cyberthreats, $57 \%$ of Thai children have experienced cyberthreats, while other nations are at risk. At $30 \%$, boys are at a $61 \%$ higher risk of $53 \%$ than girls. Concerning cyberthreats to 8-12 years old, the risks were $52 \%$ higher than for the other countries: boys were at $60 \%$ higher risk for $43 \%$ of girls $63 \%$ of Thai children 13 years and over were cybercrime, while $34 \%$ in other countries were both boys and girls. The girls had encountered this problem as well [2]. From the numbers, it can be seen that in Thailand, there is a risk of a huge rise in cyberbullying among today's teenagers, who lack the right judgment to solve problems and to respond to cyberbullying.

As a result, researchers examined developing cyber bullying skills using a flipped classroom model, with challenging learning, in an online learning ecosystem. This research considered designing a flipped classroom, with challenging learning, in an online learning ecosystem to develop cyberbullying skills. It then redesigned a flipped classroom model, with challenging learning in an online learning ecosystem, to develop cyberbullying response skills and assess the suitability of the proposed flipped classroom model by experts in the field of technology. 


\section{THEORETICAL BACKGROUND}

\section{A. Flipped Classroom}

\section{1) Definition of a flipped classroom}

The flipped classroom is one that is based on a networked cloud platform in which computer hardware and network devices, including current storage devices, can be comfortably operated in the cloud. In practice, instructors not only use desktop computers to connect to a network on a cloud platform, teaching wirelessly, but they also need to consider the network devices they can use. Wi-Fi is also available to increase the interaction between teachers and learners in the room [3] Create, Evaluate, Analyze, Apply, Understand and remember. Students study the lessons and do their homework on their own, and bring them together with the teacher in the classroom, with the tutor and other learners using proactive techniques. At the end of a lesson, the teacher renders the problem or assigns the students homework in the new chapter, and then asks the learners to repeat this until the course is complete [4]. Thus, it will become more integrated knowledge. The current trend is to use more and more technology to drive change in education in higher education institutions. It is a fundamental design that changes the structure and approach to teaching and learning through experiential knowledge, in teaching one-to-one with learners, with a variety of learning. Basically, online technology-based teaching is used to improve lessons and teaching styles. This blended learning continues to adapt to the learner's condition [5]. Choose one of the original classroom layout structures. It turns traditional classrooms upside-down; students make presentations, take online classes, then take information into class activities, learn with peers or divide work into smaller groups for better understanding [6], [7]. The flipped classroom model is a great strategy to meet demand, as teaching and learning is reversed and technology is used to increase the efficiency of teaching and learning. Learning time outside the classroom increases the engagement with the content, and when returning to class activities, their understanding is increased [8].

Therefore, to conclude, the flipped classroom is another teaching and learning alternative that is a great strategy to satisfy the learners' needs because it uses a technology-assisted approach based on a networked cloud platform with computer hardware devices. Networked devices, including devices used to store data, can operate in the cloud, with flipped classroom algorithms: Create, evaluate, analyze, implement, understand and remember, meaning students study lessons and do homework. They study with the teacher in the classroom together with other students to exchange experiences one-to-one, making it easier to understand.

\section{2) Related research of flipped classroom}

There are many related works. A component pattern has been created or a different model format about flipped classrooms; for example, Teiniker and Seuchter [9] proposed a process for a flipped classroom layout, with the first step being the transition of the original knowledge to synchronous online units. In this, there are three work processes: self-study, recording of synchronous online units and communication via social media. The second step is to move classroom instruction to the laboratory. In this process there are two elements that will lead to bringing your own device and virtual laboratory. The third step is the lab exams at the beginning of each classroom unit, which uses two elements: Step 2: BYOD and the virtual laboratory. Sezer and Abay's research [10] compared traditional and flipped classroom teaching. In this comparison, three steps replace the first step in the original form. In the traditional model, the learner has access to the teaching materials; however, in a flipped classroom model, it is divided into three steps: 1) a preparation video; 2) informing learners how to access the teaching materials; and 3), recording a video for the class and sharing this with students. The second step in the original format is that the instructor discusses with the class, and afterwards assigns the assignment. But in the flipped classroom model, the second step is a class discussion and an assignment of examinations. The third step in the original model is work is assigned; however, in the flipped classroom model, the third step is to watch the video for the next session. Cabi [11] identified the characteristics of the learning environments for experimental, flipped classrooms and conventional learning groups. The research studied the original form from the beginning of the teaching; so this started with lectures in the room, then assigning tasks in different ways. It works as the test takers stay in the room. However, in a flipped classroom, from the start, studying takes place outside of the classroom first: students study the videos and other information. They then enter the classroom to check the work. They make group presentations and study the feedback of learners. Ozdamli and Asiksoy [12] created a learner component that requires teaching to provide various digital storage platforms, cloud systems, discussion forums, Q\&A and classrooms. Inside, teachers provide information and space for students to access things such as teachers' teaching additional content or talking about teaching, letting learners find answers to different questions and allowing them to interact online or practice their skills. All of these studies either propose a model, a component or create a flipped classroom model Final Stage

\section{B. Challenge-Based Learning}

\section{1) Definition of a challenge-based learning}

The challenging-based learning model is a multidisciplinary teaching approach that encourages students to leverage technology used in everyday life to solve real-world problems. It also develops team working, self-learning and peer-based learning for solving real-world problems, and immersive learning to gain skills such as critical thinking, problem solving and collaboration [13]. It is a teaching methodology that uses innovative teaching models, using different methods to attract students to solve problems to global challenges [14]. It is a new teaching strategy that allows students to experience real-life situations at a higher level. There are high levels of uncertainty and the questions are challenging, requiring the application of previously acquired knowledge. The traditional teaching in education focuses on imparting specific and systematic knowledge through lectures, reading and repetitive work to gain accumulated knowledge of the content. The challenge-based 
learning model for skill development transforms face-to-face instruction into real-world learning scenarios [15], which is more complex than a conventional classroom. The learning challenge also includes modules on theory and practice and challenges with desired results nowadays. Thus, challenge-based learning is a cutting-edge approach to educational innovation, using real-world problems as the basis for creating at least one project, and using learning modules designed to support the project. They provide theoretical and practical knowledge to solve challenges [16], [17] and those who define the inverse learning model, such as Apple, say that learning through challenge is a collaboration. Learners help to brainstorm and to find answers, with an instructor or an expert, to analyze and solve problems together to develop a deeper knowledge of the subject being studied. They identify problems and solve problems from different perspectives for the best possible solution [18].

Therefore, it can be concluded that challenge-based learning is a learning model that brings new innovations in the world of current technology to develop skills that achieve the transition from teaching and learning face-to-face. Real-world experiences allow the students to brainstorm, to help each other think and find answers. They apply the accumulated knowledge or learning to solve the challenging problems as well as training the learners to work as a team, using self-learning and peer-to-peer learning for solving real-world problems. It uses an instructor or an expert to analyze and solve problems together. As such, the teacher will act only as a guide for the learners.

\section{2) Related research of challenge-based learning}

There are many related works that create components or different models of challenge-based learning such as that of Michel-Villarreal [19]. This design is structured into three large circles: it is challenge structuring design and then passed on to the construction of the situation brainstorming solutions; this turns into the evaluation and selecting of a solution. The outer circle is an operating process consisting of an action plan, description, feelings, evaluation, analysis and conclusion. Félix-Herrán et al. [16] defined the challenge-based learning process. They set objectives for the research method, designed an experiment, and then the results were analyzed and summarized. Rådberg's research [20] developed a challenging-learning model with the following processes, starting from the preparation process in the teaching course using the challenge lab. The first step in the preparation is as follows: 1) prepare methods and tools for research use; 2) stimulate self-leadership thinking; 3), encourage entrepreneurship ideas. The second step is to define the problem to be more challenging: 1) direction and target are set; 2) conversations with stakeholders; 3) problem identification and formulation. The final step in the research work on the C-Lab model is the conceptual design and implementation with a series of projects that support each other. Premsmith et al. [17] modeled activity that results in challenging learning in a cloud learning environment. Cloud environments include mobile devices, wireless communication, sensor alerts and self-learning. Network access, resource gathering accessibility, flexibility, evaluation standards the 5-step learning challenge is then combined and evaluated to create a challenging learning experience in a cloud-based learning environment. Apple [18] provide a framework for challenge-based learning as follows: 1) encourage big ideas; 2) questions that help develop empowerment; 3) challenge in which challengers provide guidance through questions, guiding activities and suggesting various sources of information; 4) how to fix and apply; 5) evaluation of results measurements such as assessment of learners' learning outcomes and learners' own reflections on their learning, resulting in a learning challenge and solving problems systematically. All of the research proposes a model, a component, or creates a challenging-learning model.

\section{Online Streaming Ecosystem}

\section{1) Definition of a online streaming ecosystem}

Online streaming is a service that delivers live media content such as music, motion pictures or movies over the internet [21]. It has gained great attention in recent years and has played a significant role in the management of online streaming. The important problems to consider when choosing online streaming must be: 1) the unknown online streaming area and 2) the known online streaming area, because many factors need to be analyzed for effective streaming [22]. Online streaming is a medium that people visit for entertainment, with online video streaming and live video content. This attracts people to come and watch continuously. Online streaming has enabled people to watch their favorite programs whenever they want or have the convenience of watching online streaming [23], [24]. Transmissions of video and audio signals are transmitted over the internet using modern technology to make access easier. It is an additional income channel, increasing the number of viewers and creating business opportunities as well, because viewing through streaming is unlimited: no matter where you are in the world, it can be viewed. In addition, various viewing devices such as computers, mobile phones, tablets, or even smart TVs, with streaming, have an online connection, which can also create a distinctive point of speech. It's easier to talk to viewers or to communicate with each other with the Q\&A type. Or if you want to change the camera angle and create great functions, you can do a lot more. As a result, the viewing experience of the viewer is almost no different from watching TV. There is still more to do than watching TV. This is a very new form of online broadcasting that is gaining prominence [25] so the elements of online streaming have to include a number of features such as internet speed, upload bandwidth and download bandwidth. Online streaming has some flaws in the transmission and the accuracy of the signal in live broadcasts. Also, selecting videos with high definition will affect the streaming quality. Get online when you have stable internet speeds due to efficient online streaming everything has to be related [26].

However, it can be concluded that online streaming is the transmission of video and audio signals through the internet network making use of modern technology. It is the presentation of live media content such as music, motion pictures or movies over the internet. Online streaming includes many aspects such as internet speed, upload 
bandwidth, download bandwidth, the strength of the signal, the interference. As such, the effective online streaming of all aspects must be related to each other. In addition, choosing online streaming requires analyzing two key spatial factors: 1) the unknown online streaming area; 2) the known online streaming area. This is because many factors need to be analyzed for efficient streaming. Online streaming nowadays is an additional income channel, increasing the number of viewers and creating business opportunities as well. This is because viewing through online streaming is unlimited, no matter where you are in the world. This is because there are a variety of viewing devices such as computers, mobile phones, tablets, or even smart TVs.

\section{2) Related research of online streaming ecosystem}

In related works, patterns of online streaming have been analyzed; for example, according to Statista Statistics [27] in 2020, TV viewing versus online viewing was compared. Video on the Internet from the graph of TV viewing direction, the proportion decreased in each 2009 to the present. This contrasts with the increasing proportion of news content on the internet. Respectively, Mavale and Singh [28] studied the transmission of online streaming packets. The results from the research showed YouTube ranked first in terms of streaming content, followed by Netflix and Hotstar, respectively. It can be seen that people are tending to access more content online. In their research, Lee et al. [29] looked at the factors that affect online streaming. Their research found that different factors helped promote online streaming. These were the ease of use of additional functions to help streaming options, social streaming, additional functions, streaming programs and customer service costs. Sholtes et al. [30] studied the decision-making process in order to select the streaming method suitable for learners. This included: specifying the target and scope of the stream, assessing the likelihood and the expected value, evaluating options, decision and action. In addition, Triyason and Vanijja [24] conducted a test of online streaming videos on the website. They used mobile phones to study the quality of the video and assess bandwidth use for YouTube, Netflix, Hulu, etc. From all the research, it can be seen that the teaching model and receiving of information is focused more online in an era of new technology.

\section{Cyber Bullying}

\section{1) Definition of a cyber bullying}

Cyberbullying is a common practice in today's digital life. Most cyberbullying and victimization occur in adolescence due to a lack of coping skills; this issue is a global concern [31]. Cyberbullying is defined as bullying, slander, abuse or bullying others on social media such as Facebook, Twitter, etc. [32] Moreover, cyberbullying is a common occurrence on the internet due to playing games on the internet without adult supervision. Most of them have sex, age, and basic family variables. It is one that encourage cyberbullying [33] dangerous behavior involving the misuse of technology related to the use of information and communication technologies such as e-mail, blogging, instant messages, and text message to exhibit deliberate and hostile behavior to the detriment of others [34]. In most cases, it is students who use technology or are involved in easily accessible technology such as tablets, mobile phones and laptop computers; this includes popular online platforms such as Facebook, Line, Instagram, YouTube and Twitter, where cyberbullying is the same as the old internet cyberbullying [35]. In the early 2000 s, it was easy to go online without considering punishment, increased inequality and interacting with friends online; this has now changed. Strategies for preventing and addressing cyberbullying use conventional prevention strategies [36].

To conclude, cyberbullying is a new form of cyberbullying, which now happens widely in the life of people in the digital world. Harmful behavior is associated with the misuse of technology and communication. Information and communication technology is now easily accessible such as tablets, mobile phones and laptop computers, as well as popular online platforms such as Facebook, Line, Instagram, YouTube and Twitter. They can express feelings that can be acted at any time, no place, by cyberbullying to act with intent to hurt and to destroy others. The vast majority of the victims are adolescents due to a lack of cyberbullying self-defense skills. Most of the factors contributing to cyberbullying come from playing games on the internet without adult supervision, with gender, age, and family background variables. Is an important factor.

\section{2) Related research of cyber bullying}

Related works have studied the impact factors and variables that contribute to cyberbullying. McLoughlin et al. [37] found that preventing cyberbullying involves four components: 1) to have a good idea; 2) to know the pattern of dealing with cyberbullying; 3) good mental health and 4) social cognition. Tudkuea et al. [35] conducted their study of cyberbullying behavior among secondary school students in the three southernmost provinces of Thailand. The results showed that in relation to the resulting cyberbullying behavior, it can be seen that the factors that encourage cyberbullying are: authoritarian parenting, parental violence, group violence and violent media. Yildiz Durak and Saritepeci [38] investigated sexual victimization. They found that cyberbullying can be prevented by increasing the analysis of cognitive intelligence in the brain and using digital security awareness as a tool to help prevent victimization analysis. Hellfeldt et al. [39] studied the constituents of the effects of cyberbullying. The results of the study revealed that the factors that need to be analyzed for the prevention of cyberbullying are family and friends' support, depression, anxiety and privacy. James and Yu Ono [40] researched types of cyberbullying. According to the completed research, cyberbullying consists of denigration, outing and exclusion. Schoeps et al. [41] analyzed the cyberaggression of a control group. The study found that the proportion of people controlling cyberbullying had a lower proportion of victims and known prevention patterns that increased. One direction of these was: Go here: Express, Manage, and cyberbullying is born. As a result of this study, it can be seen that many studies have been conducted on the study of behavior, factors, composition, birth patterns, prevention and experimentation of cyberbullying.

As a result of the above related research, it has been found 
that reversed classrooms and the challenging cloud-based learning model, commonly known as online learning systems, are popular now with streaming teaching. Moreover, the high ratio of cyberbullying in Thailand has given researchers the idea of conducting studies on reversed classroom learning styles with challenging learning on an ecosystem. Thus, using online learning to prevent cyberbullying.

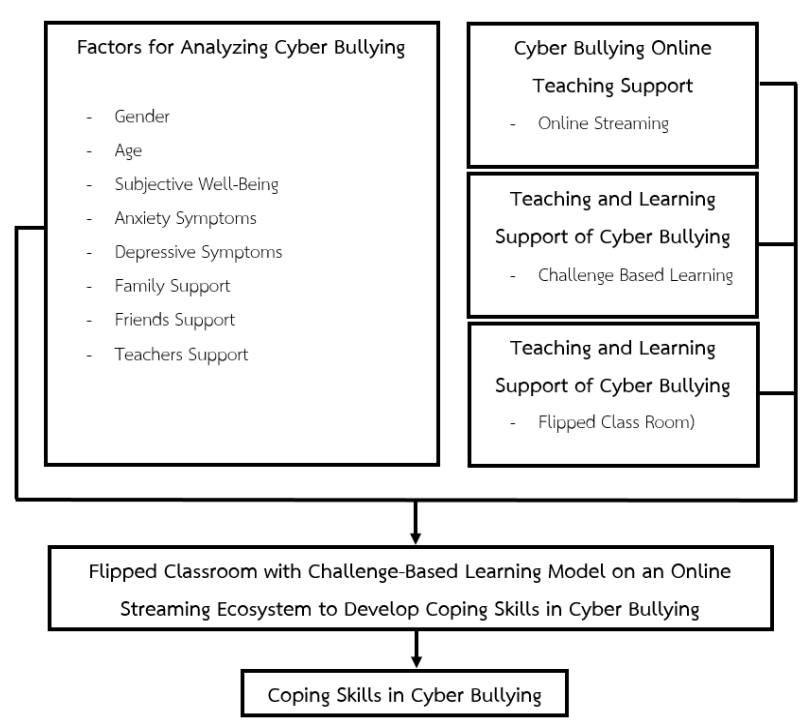

Fig. 1. Research conceptual framework.

Fig. 1 is a Research conceptual framework of Flipped Classroom with Challenge-Based Learning Model on an Online Streaming Ecosystem to Develop Coping Skills in Cyberbullying this includes the factors of Cyber Bulling, Online Streaming and Teaching and Learning used to Coping Skill in Cyber bullying.

\section{Methodology}

Phase 1: Synthesis of 41 papers and international research projects related to flipped classrooms, with a challenge-based learning management model, on an online streaming ecosystem to develop coping skills in cyberbullying between 2016 - 2020, using content analysis form and technique.

Phase 2: Design of a flipped classroom model, with a challenge-based learning management model, on an online streaming ecosystem, to develop coping skills in cyberbullying.

Phase 3: Evaluate the suitability of the developed model to develop coping skills in cyberbullying by using experts with at least five years of experience. Educational technology, information technology and research instrument are model suitability assessment from the statistics used for data analysis. It is a rating scale. The statistics used in the data analysis are the arithmetic mean and standard deviation.

\section{RESEARCH RESUltS}

\section{A. The Results of the Synthesis of Documents and Research}

Part 1: The results of the synthesis of papers and international research related to flipped classrooms, with challenge-based learning management models on an online streaming ecosystem to develop coping skills in cyberbullying.

Table I Summarize the results of the synthesis of papers and international research on cyberbullying. The results from the document analysis showed that the factors contributing to cyberbullying were gender, age, personal livelihood, anxiety symptoms, personal depression, family and friends' support, and support from teachers.

TABLE I: SYSTHESIS MATRIX OF FACTORS OF CYBER BULLYING

\begin{tabular}{|c|c|c|c|c|c|c|}
\hline $\begin{array}{c}\text { Factors } \\
\text { Cyber Bullying }\end{array}$ & $\sqrt{n}$ & $\sqrt[n]{n}$ & $\begin{array}{l}\infty \\
\stackrel{\infty}{\omega}\end{array}$ & ळે & $\Xi$ & Summarize \\
\hline$\circ$ Age & $\checkmark$ & $\checkmark$ & $\checkmark$ & $\checkmark$ & $\checkmark$ & $\checkmark$ \\
\hline o Gender & $\checkmark$ & $\checkmark$ & & $\checkmark$ & $\checkmark$ & $\checkmark$ \\
\hline o Subject Well-Being & $\checkmark$ & $\checkmark$ & $\checkmark$ & $\checkmark$ & $\checkmark$ & $\checkmark$ \\
\hline o Anxiety Symptoms & $\checkmark$ & & $\checkmark$ & $\checkmark$ & $\checkmark$ & $\checkmark$ \\
\hline $\begin{array}{l}\text { O Depressive } \\
\text { Symptoms } \\
\end{array}$ & $\checkmark$ & & $\checkmark$ & $\checkmark$ & $\checkmark$ & $\checkmark$ \\
\hline o Family Support & & $\checkmark$ & $\checkmark$ & $\checkmark$ & $\checkmark$ & $\checkmark$ \\
\hline o Friends Support & $\checkmark$ & $\checkmark$ & & $\checkmark$ & $\checkmark$ & $\checkmark$ \\
\hline ○ Teachers Support & & & $\checkmark$ & $\checkmark$ & $\checkmark$ & $\checkmark$ \\
\hline
\end{tabular}

TABLE II: SYSTHESIS MATRIX OF FACTORS OF ONLINE STREAMIMG

\begin{tabular}{|c|c|c|c|c|c|c|}
\hline $\begin{array}{c}\text { Factors } \\
\text { Online Streaming }\end{array}$ & $\widehat{\Xi}$ & 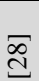 & ปे & હ & $\underset{\mathrm{J}}{戸}$ & Summarize \\
\hline$\circ$ Ease of Use & $\checkmark$ & $\checkmark$ & $\checkmark$ & $\checkmark$ & $\checkmark$ & $\checkmark$ \\
\hline o Additional & $\checkmark$ & $\checkmark$ & $\checkmark$ & $\checkmark$ & $\checkmark$ & $\checkmark$ \\
\hline o Media Options & $\checkmark$ & $\checkmark$ & $\checkmark$ & $\checkmark$ & $\checkmark$ & $\checkmark$ \\
\hline o Credibility & $\checkmark$ & $\checkmark$ & $\checkmark$ & & $\checkmark$ & $\checkmark$ \\
\hline o Cost & $\checkmark$ & & $\checkmark$ & $\checkmark$ & & $\checkmark$ \\
\hline o Customer Service & & $\checkmark$ & $\checkmark$ & $\checkmark$ & & $\checkmark$ \\
\hline o Social Trends & $\checkmark$ & $\checkmark$ & $\checkmark$ & $\checkmark$ & $\checkmark$ & $\checkmark$ \\
\hline o Content & $\checkmark$ & $\checkmark$ & $\checkmark$ & $\checkmark$ & $\checkmark$ & $\checkmark$ \\
\hline
\end{tabular}

Table II summarizes the results of the synthesis of papers and international research on online streaming to determine what factors drive the most effective online streaming for both streamers and viewers. That video the results can be concluded that online streaming has the following factors: it is easy to use and has additional applications. There is a wide variety of stunting qualities. There is reliability, cost advice or advice. Trend of the present society and most importantly, the content that is streamed online. The results of the analysis of the synthesis of techniques and methods in teaching and learning found that flipped classroom and challenging learning styles give learners a better understanding of the content and result in more effective learning than the previous model. Therefore, in this research, flipped classroom and challenge-based learning were combined on the online model to optimize learning to prevent cyberbullying. Therefore, when combined with the synthetic factor table, the flipped classroom, with challenge-based learning management model on an online streaming ecosystem, to develop coping skills in cyberbullying, was obtained in Part 2.

\section{B. Design Model}

Part 2: Design Results: The flipped classroom model, with challenge-based learning management model on an online streaming environment, to develop coping skills in cyberbullying.

Fig. 2 There are seven phases to explain the leading, process and procedure as follows:

Step 1: Defining research objectives, which is defined in 
the second clause: cognitive and practice skills used to prevent cyberbullying. It is expected that once the testers have passed the process and developed their cyberbullying response skills, they are able to recognize, understand and have the following skills.

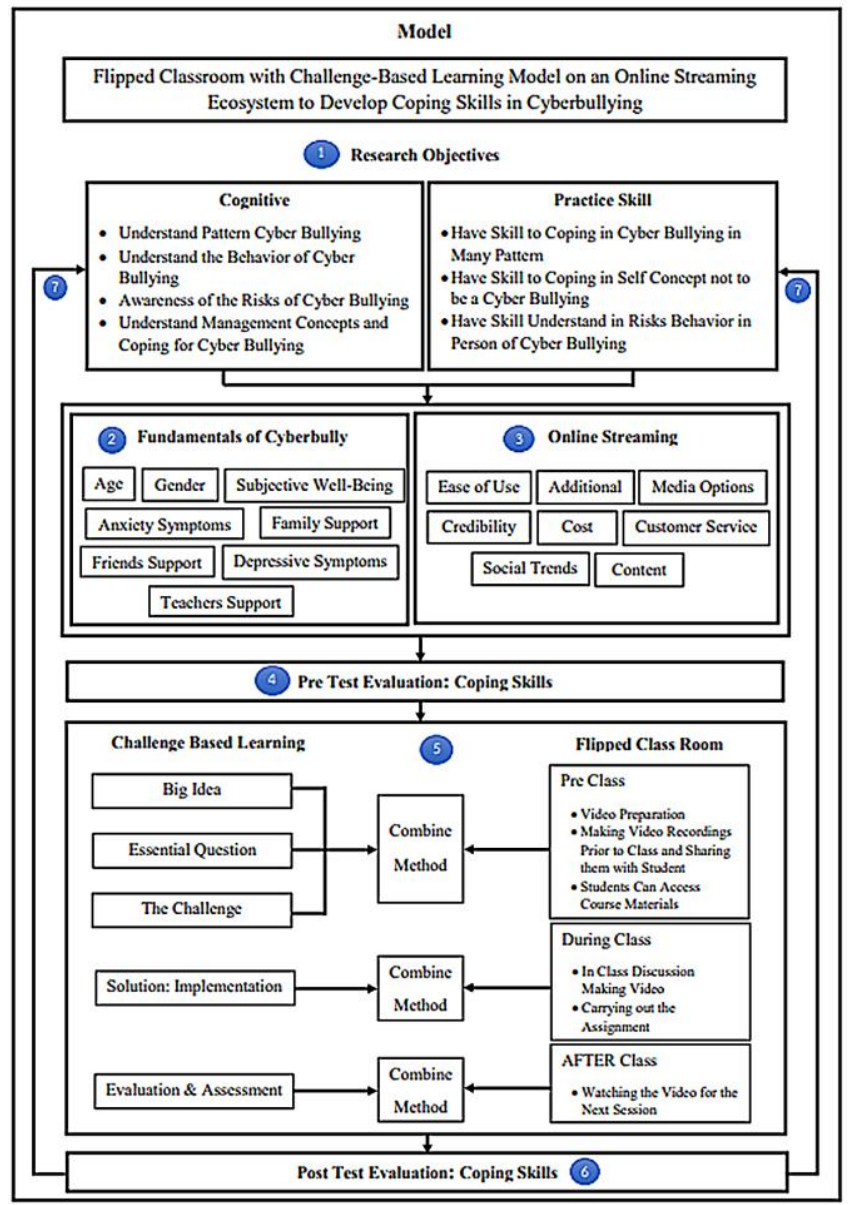

Fig. 2. Flipped classroom with challenge-based learning management model on an online streaming ecosystem to develop coping skills in cyber bullying.

\section{Cognitive skills}

- Understand cyberbullying patterns

- Understand the behavior that causes cyberbullying

- Awareness of the risks of cyberbullying

- Understand cyberbullying management concepts and approaches

\section{Practical skills}

- Skills to protect against various types of cyberbullying

- Skills to protect their ideas from cyberbullying

- Understand risks behavior in cyberbullying

Step 2: The analysis factor. Synthesis of research papers will contribute to fundamentals of cyberbullying. The synthetic analysis found that these factors affect cyberbullying: gender, age, privacy, anxiety symptoms, personal depression, family and friends' support, and support from teachers.

Step 3: The analysis factor. Synthesis of research papers that will result in the highest efficiency of online streaming. From the analysis, it was found that these factors affect online streaming: ease of use, optional function, reliability, cost, advice or advice.

Step 4: Sample selection. This is to select the sample group to develop cyberbullying coping skills, by first testing the cyberbullying skills of the sample. The groups of people will be questioned to assess who is going to be a cyberbully. If any person falls into the category of a cyberbully, they will be put into process five to further develop skills using Google Forms to create assessments for the sample groups.

Step 5: To bring a sample of people who will develop anti-cyberbullying skills using techniques and methods, combining teaching and learning techniques in the two models: challenge-based learning and flipped classroom learning as follows:

- The challenge-based learning model in the process: 1) big idea; process 2) appropriate questioning; process 3) challenging ideas and quizzes. These are the three steps of challenging learning that will be used in this case study. The students were then observed. All three processes were applied to the flipped classroom mode in the first process, which was pre-class learning, such as video preparation and teaching materials, online streaming via Facebook Live, YouTube Live, etc. Then, recording the video, video editing and uploading. It also provides a channel for learners to access various teaching materials (Server, Website, Facebook, YouTube). When the two learning models are combined in this process, it fosters a more systematic thinking process. In addition, learners ask questions that are self-challenging and are ready to study.

- The fourth process of learning in a challenging process is solution implementation. It is common to get the best possible solution to the previously created questions and to implement them in a precise manner. This will be applied in combination with the inverse learning pattern in the second process, i.e., the different forms of preparation during the teaching and learning process. The classroom discussion includes video studies taught by the instructor and questions that arise that are not understood in the video studies. When the two learning techniques are combined in this process, it achieves the best solution for teaching and learning with the sample group.

- The final process of challenge-based learning is evaluation and assessment. This was applied and combined with the flipped classroom model in the final post-teaching process. By preparing the students by instructing them in the study of the video, the two learning models are combined in this process to provide a systematic thinking process and skills in dealing with cyberbullying.

Step 6 the evaluation after the sample has entered the learning process in the fifth step of developing cognitive and practice skills to prevent cyber bullying. It uses Google Forms to create assessments to assess sample groups.

Step 7: The feedback process. This is the study of feedback analysis of the sample who have entered the learning process to develop cognitive and practical skills to prevent cyberbullying.

\section{The Evaluation Results Model}

Part 3: Evaluation results for assuring the suitability of the flipped classroom, with challenge-based learning management model on an online streaming ecosystem, to develop coping skills in cyberbullying.

Table III presents the assessment results which assure the suitability of the designed model to develop coping skills in 
cyberbullying. The evaluation results can be summarized follows as:

TABLE III: PERFORMANCE EVALUATION RESULTS

\begin{tabular}{|c|c|c|c|c|}
\hline \multirow{2}{*}{\multicolumn{2}{|c|}{ Issues }} & \multicolumn{3}{|c|}{ Level of Appropriateness } \\
\hline & & \multirow{2}{*}{\begin{tabular}{r|} 
Mean \\
4.93 \\
\end{tabular}} & \multirow{2}{*}{$\begin{array}{l}\text { S.D. } \\
\mathbf{0 . 2 3}\end{array}$} & \multirow{2}{*}{$\begin{array}{c}\text { Descript } \\
\text { on }\end{array}$} \\
\hline 1.Rese & ch objectives & & & \\
\hline \multicolumn{5}{|c|}{ 1.1 Cognitive } \\
\hline 1.1 .1 & $\begin{array}{l}\text { Understand Pattern Cyber } \\
\text { Bullying }\end{array}$ & 4.90 & 0.32 & Highest \\
\hline 1.1 .2 & $\begin{array}{l}\text { Understand the Behavior of } \\
\text { Cyber Bullying }\end{array}$ & 4.90 & 0.32 & Highest \\
\hline 1.1 .3 & $\begin{array}{l}\text { Awareness of the Risks of } \\
\text { Cyber Bullying }\end{array}$ & 4.90 & 0.32 & Highest \\
\hline 1.1 .4 & $\begin{array}{l}\text { Understand Management } \\
\text { Concepts and Coping for } \\
\text { Cyber Bullying }\end{array}$ & 5.00 & 0.00 & Highest \\
\hline \multicolumn{5}{|c|}{ 1.2 Practice Skill } \\
\hline 1.2 .1 & $\begin{array}{l}\text { Have Skill to Coping in } \\
\text { Cyber Bullying in Many } \\
\text { Pattern }\end{array}$ & 5.00 & 0.00 & Highest \\
\hline 1.2 .2 & $\begin{array}{l}\text { Have Skill to Coping in } \\
\text { Self Concept not to be a } \\
\text { Cyber Bullying }\end{array}$ & 4.90 & 0.32 & Highest \\
\hline 1.2 .3 & $\begin{array}{l}\text { Have Skill Understand in } \\
\text { Risks Behavior in Person of } \\
\text { Cyber Bullying }\end{array}$ & 4.90 & 0.32 & Highest \\
\hline \multicolumn{2}{|c|}{ 2. Factors of Cyber Bullying } & 4.79 & $\mathbf{0 . 4 3}$ & Highest \\
\hline 2.1 & Gender & 4.70 & 0.67 & Highest \\
\hline 2.2 & Age & 5.00 & 0.00 & Highest \\
\hline 2.3 & Subject Well-Being & 4.80 & 0.42 & Highest \\
\hline 2.4 & Anxiety Symptoms & 4.90 & 0.32 & Highest \\
\hline 2.5 & Depressive Symptoms & 4.70 & 0.48 & Highest \\
\hline 2.6 & Family Support & 4.80 & 0.42 & Highest \\
\hline 2.7 & Friends Support & 4.80 & 0.42 & Highest \\
\hline 2.8 & Teachers Support & 4.80 & 0.70 & Highest \\
\hline \multicolumn{2}{|c|}{ 3. Factors of Online Streaming } & 4.81 & 0.34 & Highest \\
\hline 3.1 & Ease of Use & 4.80 & 0.42 & Highest \\
\hline 3.2 & Additional & 4.60 & 0.52 & Highest \\
\hline 3.3 & Media Options & 4.90 & 0.32 & Highest \\
\hline 3.4 & Credibility & 5.00 & 0.00 & Highest \\
\hline 3.5 & Cost & 4.50 & 0.71 & High \\
\hline 3.6 & Customer Service & 4.90 & 0.32 & Highest \\
\hline 3.7 & Social Trends & 4.80 & 0.42 & Highest \\
\hline 3.8 & Content & 5.00 & 0.00 & Highest \\
\hline \multicolumn{2}{|c|}{ 4. Pre Test Evaluation: Coping Skill } & 4.90 & 0.32 & Highest \\
\hline \multicolumn{2}{|c|}{$\begin{array}{l}\text { 5. Flipped Classroom with } \\
\text { Challenge-Based Learning } \\
\text { Management Model }\end{array}$} & 4.95 & 0.16 & Highest \\
\hline \multicolumn{5}{|c|}{5.1 Step 1} \\
\hline 5.1 .1 & $\begin{array}{l}\text { Preparing information } \\
\text { before studying in the } \\
\text { classroom }\end{array}$ & 4.90 & 0.32 & Highest \\
\hline 5.1 .2 & $\begin{array}{l}\text { Creating new Big Idea and } \\
\text { challenging ideas }\end{array}$ & 4.90 & 0.32 & Highest \\
\hline 5.1 .3 & Essential Question & 4.90 & 0.32 & Highest \\
\hline 5.1 .4 & The Challenge & 5.00 & 0.00 & Highest \\
\hline \multicolumn{5}{|c|}{5.2 Step 2} \\
\hline 5.2 .1 & $\begin{array}{l}\text { Preparation of variations in } \\
\text { During Class }\end{array}$ & 5.00 & 0.00 & Highest \\
\hline 5.2 .2 & Solution: Implementation & 5.00 & 0.00 & Highest \\
\hline \multicolumn{5}{|c|}{5.3 Step 3} \\
\hline 5.3 .1 & Post-Instructional Process & 5.00 & 0.00 & Highest \\
\hline 5.3 .2 & Evaluation \& Assessment & 4.90 & 0.32 & Highest \\
\hline \multicolumn{2}{|c|}{$\begin{array}{l}\text { 6. Port Test Evaluation: Coping } \\
\text { Skill }\end{array}$} & 5.00 & 0.00 & Highest \\
\hline \multicolumn{2}{|c|}{ 7. Feedback } & 5.00 & 0.00 & Highest \\
\hline \multicolumn{2}{|c|}{$\begin{array}{l}\text { 8. Flipped Classroom with } \\
\text { Challenge-Based Learning Model } \\
\text { on an Online Streaming Ecosystem } \\
\text { to Develop Coping Skills in Cyber }\end{array}$} & 5.00 & $\mathbf{0 . 0 0}$ & Highest \\
\hline
\end{tabular}

\begin{tabular}{|c|c|c|c|c|}
\hline \multicolumn{5}{|c|}{ Bullying } \\
\hline 8.1 & $\begin{array}{l}\text { Suitability for Flipped } \\
\text { Classroom with } \\
\text { Challenge-Based Learning } \\
\text { Model on an Online } \\
\text { Streaming Ecosystem to } \\
\text { Develop Coping Skills in } \\
\text { Cyber Bullying }\end{array}$ & 5.00 & 0.00 & Highest \\
\hline 8.2 & $\begin{array}{l}\text { Suitability of developing } \\
\text { cyber bullying coping skills }\end{array}$ & 5.00 & 0.00 & Highest \\
\hline \multicolumn{2}{|r|}{ Total } & 4.88 & 0.22 & Highest \\
\hline
\end{tabular}

1) The objective was to create a flipped classroom model, with challenge-based learning management model on an online streaming ecosystem, to develop coping skills in cyberbullying. Overall, it was found that it was at the most appropriate level $($ Mean $=4.93, \mathrm{SD}=0.23)$. When examining the objectives of the individual patterns, it was found that understanding management concepts and coping for cyberbullying and have skill to coping in cyberbullying in many pattern is optimal (Mean $=5.00$, $\mathrm{SD}=0.00)$

2) Factors' selection results contributing to cyberbullying. Overall, it was found that the optimal (Mean $=4.73$, S.D. $=0.43$ ). When examining the factors contributing to individual cyberbullying, age was found to be the most appropriate $($ Mean $=5.00$, S.D. $=0.00)$.

3) Factors' selection results in online streaming overall, it was found to be at the most appropriate level (Mean = 4.81, S.D. = 0.34). When examining the factors in online streaming, it was found that the aspects of credibility and content were the most appropriate (Mean $=5.00$, S.D. $=0.00)$.

4) The results of the pattern design, with the sample being evaluated first, whether they are cyberbullies in the online world isn't. The evaluation results found that the optimal level $($ Mean $=4.90$, S.D. $=0.33)$.

5) The results of selection factors of flipped classroom model, with challenge-based learning management model, are as follows. Overall, it was found that the optimal level $($ Mean $=4.95$, S.D. $=0.16)$ when examining factors of flipped classrooms combined with challenge-based learning. Each question found that the challenge and preparation during class, solution implementation, and post-instructional process were the most appropriate $($ Mean $=5.00$, S.D. $=0.00)$.

6) The results of the pattern design were evaluated after the development of cyberbullying skills. The evaluation results were found that the optimal levels (Mean $=5.00$, S.D. $=0.00$ ).

7) The results of the design of the form, providing feedback to the design objectives, showed that the most appropriate level $($ Mean $=5.00$, S.D. $=0.00)$.

8) The results of the design of the flipped classroom model to develop coping skills in cyberbullying, in the field of implementation and development to achieve cyberbullying prevention, were found to be at the optimal level $($ Mean $=5.00$, S.D. $=0.00)$

Overall, the suitability of the designed flipped classroom, with challenge-based learning management model on an online streaming ecosystem, to develop coping skills was found to be most appropriate $($ Mean $=4.88$, S.D. $=0.22$ ) 


\section{CONCLUSION}

The main purpose of this research is to create a flipped classroom with a challenge-based learning management model on an online streaming ecosystem can develop coping skills. To this end, introduction of the flipped classroom model resulted in more develop coping skills and promoted changing the role in learning process. In addition, the selection of inputs of factors that resulted in cyberbullying was the most appropriate level. The factors were: gender, age, subject well-being, anxiety symptoms, depressive symptoms, and family, friends and teachers' support. And our findings it was found that the selection of inputs in online streaming has the highest level of suitability. It consists of the following factors: Ease of Use, Additional, Media Options, Credibility, Cost, Customer Service, Social Trends and Content. And flipped classroom teaching combined with challenge-based learning was the most appropriate level. Therefore, it can be concluded that the selection of flipped classroom teaching combined with challenge-based learning is appropriate for skill development. To be effective, flipped classes must be designed with careful planning that considers alignment to learning outcomes and assessment.

In this section we used Ten experts assessed the suitability of the flipped classroom model, with challenge- based learning management model on an online streaming ecosystem, to improve overall cyberbullying response skills. These experts all had more than five years of experience in related fields; they found that the designed flipped classroom model is very suitable to develop anti-cyberbullying skills.

Future research will use the Flipped Classroom with Challenge-Based Learning Model on an Online Streaming to the test and put it to practice to promote cyber-bullying skills development.

\section{CONFLICT OF INTEREST}

The authors declare no conflict of interest.

\section{AUTHOR CONTRIBUTIONS}

Phisit Pornpongtechavanich studied relevant research documents, analyzed the data, conducted the research, summarized and wrote the paper. Kawitsara Eumbunnapong co-analyzed the data, co-summarized and co-wrote the paper. Pallop Piriyasurawong served as research advisors. All authors had approved the final version.

\section{ACKNOWLEDGMENT}

Rajamangala University of Technology Rattanakosin (Wang Klai Kangwon Campus), Mahidol University and King Mongkut's University of Technology North Bangkok for supporting this study and thank you all the experts for evaluate the Model in this research.

\section{REFERENCES}

[1] Datareportal. (2020). [Online]. Available: https://datareportal.com/reports/digital-2020-global-digital-overview

[2] P. Lerksirinukul. (2020). [Online]. Available: https://www.salika.co/2020/06/18/cyberbulling-survey-and-knowledg e-sharing-for-thais/

[3] J. Leng, B. Zhu, and M. Zhang, "Analysis on the cost of implementing the flipped classroom model in universities," in Proc. the 2020 9th international conference on educational and information technology, no. 3, pp. 55-61, 2020, doi: 10.1145/3383923.3383947.

[4] V. Halitoglu, "A flipped-classroom model in teaching Turkish as a foreign language," Int. Online J. Educ. Sci., vol. 12, no. 1, 2020, doi: 10.15345/iojes.2020.01.005.

[5] M. Mojtahedi, I. Kamardeen, H. Rahmat, and C. Ryan, "Flipped classroom model for enhancing student learning in construction education," J. Civ. Eng. Educ., vol. 146, no. 2, p. 05019001, 2020, doi: 10.1061/(asce)ei.2643-9115.0000004.

[6] K. Nahar and R. Chowdhury, "Effectiveness of flipped classroom model in distance learning," in Proc. 30th Annu. Conf. Australas. Assoc. Eng. Educ. (AAEE 2019), 2019.

[7] M. A. Trpkovska, L. A. Bexheti, and B. Cico, "Enhancing flipped classroom model implementation," 2017 6th Mediterr. Conf. Embed. Comput. MECO 2017 - Incl. ECYPS 2017, Proc., doi: 10.1109/MECO.2017.7977138.

[8] S. Y. Rucker, Z. Ozdogan, and M. Al Achkar, "Flipped classroom model for learning evidence-based medicine," Adv. Med. Educ. Pract., vol. 8, pp. 619-625, 2017, doi: 10.2147/AMEP.S142233.

[9] E. Teiniker and G. Seuchter, "Improving the flipped classroom model by the use of inductive learning," IEEE Glob. Eng. Educ. Conf. EDUCON, pp. 512-520, 2020, doi: 10.1109/EDUCON45650.2020.9125373.

[10] B. Sezer and E. Abay, "Looking at the impact of the flipped classroom model in medical education," Scand. J. Educ. Res., vol. 63, no. 6, pp. 853-868, 2019, doi: 10.1080/00313831.2018.1452292.

[11] E. Cab1, "The impact of the flipped classroom model on students' academic achievement," Int. Rev. Res. Open Distance Learn., vol. 19, no. 3, 2018.

[12] F. Ozdamli and G. Asiksoy, "Flipped classroom approach," World J. Educ. Technol., vol. 8, no. 2, p. 98, 2016, doi: 10.18844/wjet.v8i2.640.

[13] E. L. Vilalta-Perdomo, R. Michel-Villarreal, G. Lakshmi, and C. Ge, "Challenge-based learning," no. April, pp. 150-176, 2020, doi: 10.4018/978-1-7998-2562-3.ch007.

[14] May Portuguez Castro and Marcela Georgina Gómez Zermeño, 2020.pdf.

[15] I. E. Eraña-Rojas, M. V. López Cabrera, E. Ríos Barrientos, and J. Membrillo-Hernández, "A challenge based learning experience in forensic medicine," J. Forensic Leg. Med., vol. 68, no. September, 2019, doi: 10.1016/j.jflm.2019.101873.

[16] L. C. Félix-Herrán, A. E. Rendon-Nava, and J. M. Nieto Jalil, "Challenge-based learning: an I-semester for experiential learning in Mechatronics Engineering," International Journal on Interactive Design and Manufacturing, vol. 13, no. 4. pp. 1367-1383, 2019, doi: 10.1007/s12008-019-00602-6.

[17] J. Premsmith, P. Wannapiroon, and P. Nilsook, "Design of challenge-based learning activities on ubiquitous cloud learning environment," vol. 11, no. 1, pp. 368-375, 2017.

[18] Apple, "Challenge based learning: A classroom guide," Apple Inc, pp. 1-40, 2010.

[19] R. Michel-villarreal, "Embedding industry 4.0 in operations management education using a Challenge-based Learning approach," Euroma, no. June, pp. 1-10, 2020.

[20] Kamilla Kohn Rådberg and etc, 2018.pdf.

[21] M. Lee, H. Choi, D. Cho, and H. Lee, "Cannibalizing or complementing? The impact of online streaming services on music record sales," Procedia Comput. Sci., vol. 91, no. Itqm, pp. 662-671, 2016, doi: 10.1016/j.procs.2016.07.166.

[22] P. Zhou, X. Hu, P. Li, and X. Wu, "OFS-Density: A novel online streaming feature selection method," Pattern Recognit., vol. 86, pp. 48-61, 2019, doi: 10.1016/j.patcog.2018.08.009.

[23] G. Misra, A. Agarwal, K. Agarwal, and O. Pabshetwar, "Is the online internet streaming going to kill TV/cable by 2025?" Am. J. Electr. Electron. Eng., vol. 7, no. 4, pp. 91-93, 2019, doi: 10.12691/ajeee-7-4-1.

[24] D. Pal, T. Triyason, and V. Vanijja, "Quality evaluation of high resolution videos viewed on a mobile device in an online streaming environment," 11th IEEE Int. Conf. Adv. Networks Telecommun. Syst. ANTS 2017, no. June, pp. 1-6, 2018, doi: 10.1109/ANTS.2017.8384172.

[25] Obsmoscou. (2018). [Online]. Available: http://www.obsmoscou.net

[26] D. You et al., "Online streaming feature selection via conditional independence," Appl. Sci., vol. 8, no. 12, pp. 1-25, 2018, doi: 10.3390/app8122548.

[27] Statista. (2020). [Online]. Available: http://www.fipp.com/news/chart-week-tv-reign-nearing-end/ 
[28] D. S. Mavale and R. Singh, "Study of perception of college going young adults towards online streaming services," Int. J. Eng. Manag. Res., vol. 10, no. 01, pp. 111-115, 2020, doi: 10.31033/ijemr.10.1.18.

[29] C. C. Lee, P. Nagpal, S. G. Ruane, and H. S. Lim, "Communications of the IIMA factors affecting online streaming subscriptions subscriptions," Commun. IIMA, vol. 16, no. 1, p. 25, 2018.

[30] J. S. Sholtes, C. Ubing, T. J. Randle, J. Fripp, D. Cenderelli, and D. C. Baird, "Managing infrastructure in the stream environment," J. Am. Water Resour. Assoc., vol. 54, no. 6, pp. 1172-1184, 2018, doi: 10.1111/1752-1688.12692.

[31] Y. Ding, D. Li, X. Li, J. Xiao, H. Zhang, and Y. Wang, "Profiles of adolescent traditional and cyber bullying and victimization: The role of demographic, individual, family, school, and peer factors," Comput. Human Behav., vol. 111, no. May, p. 106439, 2020, doi: 10.1016/j.chb.2020.106439.

[32] ETDA: Electronic Transactions Development Agency. (2020). [Online]. https://www.etda.or.th/content/stop-cyberbullying-2019.html

[33] Z. Teng, Q. Nie, Z. Zhu, and C. Guo, "Violent video game exposure and (cyber)bullying perpetration among Chinese youth: The moderating role of trait aggression and moral identity," Comput. Human Behav., vol. 104, no. November 2019, p. 106193, 2020, doi: 10.1016/j.chb.2019.106193.

[34] C. M. Kokkinos and N. Antoniadou, "Cyber-bullying and cyber-victimization among undergraduate student teachers through the lens of the general aggression model," Comput. Human Behav., vol. 98 , no. April, pp. 59-68, 2019, doi: 10.1016/j.chb.2019.04.007.

[35] T. Tudkuea, K. Laeheem, and R. Sittichai, "Development of a causal relationship model for cyber bullying behaviors among public secondary school students in the three southern border provinces of Thailand," Child. Youth Serv. Rev., vol. 102, no. December 2018, pp. 145-149, 2019, doi: 10.1016/j.childyouth.2019.05.013.

[36] B. A. Spears, C. Taddeo, and A. Barnes, Online Social Marketing Approaches to Inform Cyber/Bullying Prevention and Intervention: What Have We Learnt? Elsevier Inc., 2018.

[37] L. T. McLoughlin, J. Lagopoulos, and D. F. Hermens, "Cyberbullying and adolescent neurobiology," Front. Psychol., vol. 11, no. June, pp. 1-7, 2020, doi: 10.3389/fpsyg.2020.01511.

[38] H. Y. Durak and M. Saritepeci, "Examination of the relationship between cyberbullying and cyber victimization," J. Child Fam. Stud., vol. 29, no. 10, pp. 2905-2915, 2020, doi: 10.1007/s10826-020-01768-4.

[39] K. Hellfeldt, L. López-Romero, and H. Andershed, "Cyberbullying and psychological well-being in young adolescence: the potentia protective mediation effects of social support from family, friends, and teachers," Int. J. Environ. Res. Public Health, vol. 17, no. 1, 2020, doi: 10.3390/ijerph17010045.

[40] B. James and D. Yuono, "Pusat pencegahan cyberbullying: pencegahan cyberbullying melalui karya arsitektur," J. Sains, Teknol. Urban, Perancangan, Arsit., vol. 1, no. 2, p. 1359, 2020, doi: 10.24912/stupa.v1i2.4450.
[41] K. Schoeps, L. Villanueva, V. J. Prado-Gascó, and I. Montoya-Castilla, "Development of emotional skills in adolescents to prevent cyberbullying and improve subjective well-being," Front. Psychol., vol. 9, no. OCT, pp. 1-12, 2018, doi: 10.3389/fpsyg.2018.02050.

Copyright $\odot 2021$ by the authors. This is an open access article distributed under the Creative Commons Attribution License which permits unrestricted use, distribution, and reproduction in any medium, provided the original work is properly cited (CC BY 4.0).

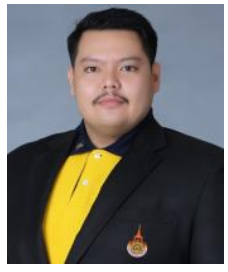

Phisit Pornpongtechavanich is currently a lecturer at the Faculty of Industry and Technology, Rajamangala University of Technology Rattanakosin Wang Klai Kangwon Campus (RMUTR_KKW), Thailand. In 2012, he received his bachelor of technology in information technology from RMUTR_KKW. He obtained a scholarship to study in Thailand and then received a master of science in information technology from KingMongkut's University of Technology North Bangkok (KMUTNB) in 2014. And is studying for doctor of philosophy (Ph.D.), Division of Information and Communication Technology for Education from KingMongkut's University of Technology North Bangkok (KMUTNB). His research interests include security, deep learning, artificial neuron networks, deep neural network, VoIP quality measurement, QoE/QoS, 3G/4G/5G, mobile networks and multimedia communication.

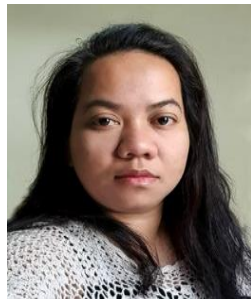

Kawitsara Eumbunnapong is currently an academic in the production of medical media a Faculty of Medicine Siriraj Hospital Mahidol University. Graduated with a bachelor's degree from Mahidol University and graduated with a master's degree from King Mongkut's University North Bangkok. She is also interested in the production of medical instructional materials, medical drawing, patient imaging and technology for education.

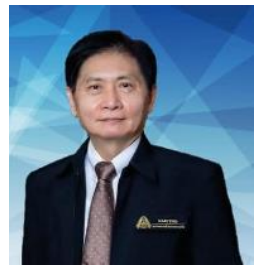

Pallop Piriyasurawong is an associate professor of division of information and communication technology for education, Faculty of Technical Education, King Mongkut's University of Technology North Bangkok (KMUTNB), Bangkok, Thailand, $10800 \mathrm{He}$ has experience in many positions such as computer curriculum specialist at Basic Education Institute for the Promotion of Teaching Science and Technology (IPST). And he is chairman of the Board of Courseware Series of Teaching in Undergraduate Information Technology Systems, e-Learning of Office the Higher Education Commission. Also, he is a head of information and communication technology for education. 